\title{
Jasmonates promote enhanced production of bioactive caffeoylquinic acid derivative in Eclipta prostrata (L.) L. hairy roots
}

\author{
Geveraldo Maciel ${ }^{1}$. Adriana Aparecida Lopes ${ }^{1}$. Charles L. Cantrell ${ }^{2}$. Suzelei de Castro França ${ }^{1}$. \\ Bianca Waleria Bertoni ${ }^{1} \cdot$ Miriam Verginia Lourenço ${ }^{1}{ }^{10}$
}

Received: 29 September 2021 / Accepted: 16 November 2021 / Published online: 22 November 2021

(c) The Author(s), under exclusive licence to Springer Nature B.V. 2021

\begin{abstract}
Eclipta prostrata (L.) L. is widely used in traditional medicine for treatment of hepatitis, poisoning from snake bites and viral infections. Pharmacological studies confirmed its antioxidant, anti-inflammatory and anticancer activities. The efficacy of E. prostrata (L.) L. extracts has been correlated to phenylpropanoids such as flavonoids, coumestans and caffeoylquinic acid derivatives. In this work, the production of wedelolactone, demethylwedelolactone and 3,5-di-O-caffeoylquinic acid (3,5-diCQA) in hairy root cultures of E. prostrata (L.) L. C19 clone was increased after addition of eliciting agents jasmonic acid (JA) or methyl jasmonate (MeJA) at multiple concentrations. Cultures elicited with $100 \mu \mathrm{M}$ of JA saw a 5.2 fold increase in wedelolactone (from 0.72 to $3.72 \mathrm{mg} / \mathrm{g} \mathrm{d.w.)}$, a 1.6 fold increase in demethylwedelolactone (from 5.54 to $9.04 \mathrm{mg} / \mathrm{g} \mathrm{d}$.w.) and a 2.47 fold increase in 3,5-diCQA (from 18.08 to $44.71 \mathrm{mg} / \mathrm{g} \mathrm{d}$.w.). Obtained data validate the potential of E. prostrata (L.) L. hairy root cultures as a production system of wedelolactone, demethylwedelolactone and especially 3,5-diCQA, which has recently been reported to possess activity against coronavirus disease (Covid-19) by in silico computational studies.
\end{abstract}

\section{Key message}

The goal of this work was to evaluate the effect of jasmonic acid (JA) or methyl jasmonate (MeJA) on wedelolactone, demethylwedelolactone and 3,5-di-O-caffeoylquinic acid (anti-Covid-19 drug candidate) production from hairy root cultures of Eclipta prostrata (L.) L. C19 clone.

Keywords Eclipta prostrata (L.) L. · Hairy roots · Covid-19 · Coumestans $\cdot$ Jasmonates $\cdot$ Caffeoylquinic acid derivatives

\section{Introduction}

In vitro culture techniques are an alternative for rapid multiplication of rare plant genotypes, plant genome transformation, and production of plant bioactives (Espinosa-Leal et al. 2018). They provide unique opportunities for the use of biotechniques that may increase plant secondary metabolite production. Some methods can improve the technique such

Communicated by Wagner Campos Otoni.

Miriam Verginia Lourenço

mvlouren@gmail.com

1 Biotechnology Unit, Universidade de Ribeirão Preto (UNAERP), Ribeirão Preto, SP 14096-900, Brazil

2 Natural Products Utilization Research Unit, United States Department of Agriculture - Agricultural Research Service (USDA-ARS), University, Oxford, MS 38655, USA as the use of plant transformation generation techniques. In response to Rhizobium rhizogenes genetic transformation, susceptible plants present a phenotype alteration known as hairy roots (Cardarelli et al. 1987; Spena et al. 1987; Schmülling et al. 1988). Applications of some elicitors and combinations of different stress stimuli can enhance the production of bioactive molecules by elicitor effects. Jasmonates are considered widespread elicitors since they affect several signaling pathways stimulating the production of different classes of secondary metabolites in plants and microorganisms (Lourenço et al. 2016). The more active derivative methyl jasmonate (MeJA) and the less active cis-jasmonate and dihydrojasmonic acid are the main plant stress compounds involved in the signaling of defense responses, primarily due to induction of genes involved in phytoalexin and phenolics biosynthesis (Sák et al. 2021).

Eclipta prostrata (L.) L., native to Brazil and other tropical and subtropical regions of the world, is an annual 
herbaceous species from the Asteraceae family (Souza et al. 2003). This species is widely used in traditional medicine against several diseases like hepatitis (Lu et al. 2016), poisoning by snake bites and treatment of viral infections (Manvar et al. 2012). Moreover, pharmacological studies have reported E. prostrata (L.) L. antioxidant, anti-inflammatory and anticancer activities (Chaudhary et al. 2011; Yuan et al. 2013; Ali et al. 2016). The efficacy of E. prostrata (L.) L. has been correlated to chemical constituents present in its extracts such as flavonoids (Malla et al. 2013), thiophenes (Wu et al. 2008; Han et al. 2013), coumarins (Zhang and Guo 2001), triterpenoid saponins (Yahara et al. 1994), steroids (Cheng and Hu 2010) and coumestans (Diogo et al. 2009). The coumestans wedelolactone (WL) and demethylwedelolactone (DWL) isolated from E. prostrata (L.) L. are the most explored compounds from the point-of-view of biological activity, displayed potency and selective inhibition activity of lipoxygenase subcategories 5-lipoxigenase (Wagner and Fessler 1986) and a trypsin-inhibiting activity that may be associated to the anti-inflammatory potential of the species (Syed et al. 2003). WL and DWL suppressed cancer cell motility, inhibiting the invasion and growth of breast cancer cells and they also exhibited an anti-invasive effect on human SK-HEP-1 hepatoma cells. Also, DWL suppressed lung cancer cells metastasis in mice (Lee et al. 2012). Moreover, the association of WL with the flavonoids apigenin and luteolin restrained both the in vitro and in vivo growth of prostate cancer cells (Lin et al. 2007; Tsai et al. 2009).

Eclipta prostrata (L.) L. produces phenolic acids such as chlorogenic acid and its derivative 3,5-di-O-caffeoylquinic acid (3,5-diCQA) (Lee et al. 2010). Chlorogenic acid and its derivatives have demonstrated several biological activities, such as antioxidant, antibiosis, anti-inflammatory, antivirus, and antitumor activities (Huang et al. 2014; Ali et al. 2017; Liu et al. 2018; Devrnja et al. 2020). More recently, studies by molecular docking using a serine-type protease (Mpro), a SARS-CoV-2 virus polyprotein, showed that the obtained binding energies of 3,5-diCQA were closed to remdesivir (antiviral compound), indicating stronger binding to Mpro protein and promising antiviral compounds that could treat Covid-19 (Shah et al. 2021). Additionally, the 3,5-diCQA was related as an emergency drug that can be used for targeting 2'-O-ribose methyltransferase of SARS-CoV-2 in silico (Sumon et al. 2021). In previous work, our group investigated the suitability of E. prostrata (L.) L. hairy root cultures as a system for the production of the coumestans wedelolactone (WL) and demethylwedelolactone (DWL) and a hairy root clone named $\mathrm{C} 19$ was selected considering its superior potential for producing coumestans (Diogo et al. 2009). Aiming to increase yields of bioactive compounds, we decided to evaluate the eliciting effect of JA and MeJA in E. prostrata (L.) L. hairy root $\mathrm{C} 19$ during the biosynthesis of coumestans (WL and DWL) and especially 3,5-diCQA (Fig. 1), an promising anti-covid-19 compound.

\section{Materials and methods}

\section{Chemicals}

The chemical elicitors JA (jasmonic acid), MeJA (methyl jasmonate), and WL (wedelolactone) were purchased from Sigma-Aldrich ${ }^{\circledR}$ (St. Louis, MO).

\section{Maintenance of $E$. prostrata (L.) L. C19 hairy root clone}

Eclipta prostrata (L.) L. hairy root $\mathrm{C} 19$ clone was obtained by infecting E. prostrata (L.) L. micropropagated seedlings with $R$. rhizogenes LBA 9796 (Diogo et al. 2009). C19 clone was selected because its roots presented higher production of the coumestans WL and DWL. Monthly subculture of the $\mathrm{C} 19$ clone in MS liquid culture medium (Murashige and Skoog 1962) under agitation (100 rpm) at $24{ }^{\circ} \mathrm{C}$ in the dark in order to maintenance of clone. To determine the most appropriate period to add the eliciting agent to the culture, a growth curve was established inoculating hairy roots $(2 \mathrm{~g})$ into $100 \mathrm{ml}$ of MS medium, in the same conditions as above. Hairy root samples were collected periodically at 3-day intervals, weighed and dried in a circulating air oven to determine fresh and dry weight of samples.

\section{Determination of the kinetics of growth of $E$. prostrata (L.) L. hairy root}

For determining the growth kinetics, the hairy roots $(2.00 \pm 0.01 \mathrm{~g})$ were inoculated into $100 \mathrm{~mL}$ of MS liquid culture medium. Cultures were kept in the dark at $25 \pm 1{ }^{\circ} \mathrm{C}$ under agitation (100 rpm). Two independent experiments were carried out in triplicate flasks. Samples were collected at 3-day intervals up to the 36th day of culture. After determining root fresh weight, the material was dried at $45{ }^{\circ} \mathrm{C}$ in a circulating air oven for $24 \mathrm{~h}$ to determine the root dry weight.

\section{Elicitation of $E$. prostrata (L.) L. hairy roots with JA or MeJA}

For the elicitation assays, hairy roots $(1.0 \mathrm{~g})$ were inoculated into $100 \mathrm{ml}$ of MS liquid medium and maintained as above. On the 21st day, cultures were supplemented with two different concentrations $(100 \mu \mathrm{M}$ or $140 \mu \mathrm{M})$ of JA or MeJA (Wiktorowska et al. 2010) and kept under agitation as mentioned above. One, two and four days after addition of elicitor agent, samples were collected and dried in 
a circulating air oven and then extracted to determine WL, DWL and 3,5-diCQA levels. Analysis of variance (ANOVA) was carried out to compare mean values and linear regression curves were constructed using SISVAR 5.3 software (Ferreira 2011). Mean values were compared by the ScottKnott test $(\mathrm{p}<0.05)($ Scott and Knott 1974).

\section{Quantification of WL, DWL and 3,5-diCQA in E. prostrata (L.) L. hairy root C19 clone}

For quantification of target secondary metabolites produced by E. prostrata (L.) L. hairy roots, dried roots $(200 \mathrm{mg})$ were sonicated with $5.0 \mathrm{~mL} \mathrm{MeOH}: \mathrm{H}_{2} \mathrm{O}$ (7: 3) for $30 \mathrm{~min}$. The extracts were then filtered through a $0.45 \mu \mathrm{m}$ membrane and injected into a HPLC Shimadzu LC10AD vp (Shimadzu, Japan) coupled with a photodiode array detector. A Phenomenex Quinetex C- 18 column $(250 \times 4.0 \mathrm{~mm}, 5 \mu \mathrm{m}$ particles $)$ was used for the analyses. The solvent system consisted of $0.1 \%$ acetic acid in water (A) and methanol (B). The analysis was performed on a linear gradient ranging from $10 \% \mathrm{~B}$ to $66 \% \mathrm{~B}$ in $32 \mathrm{~min}$, returning to $10 \% \mathrm{~B}$ for up to $35 \mathrm{~min}$. concluding the analysis in $40 \mathrm{~min}$. The injection volume was $20 \mu \mathrm{L}$ and visualization at 330 and $350 \mathrm{~nm}$. Quantification was performed by external standardization using standard curves from WL (at concentrations of $0.063 \mathrm{mg} /$ $\mathrm{mL}$ to $0.50 \mathrm{mg} / \mathrm{mL}$ ) and 3,5-diCQA (at concentrations of $0.063 \mathrm{mg} / \mathrm{mL}$ to $1.00 \mathrm{mg} / \mathrm{mL}$ ).

\section{Isolation and structural elucidation of 3,5-diCQA from E. prostrata (L.) L. hairy root C19 clone}

C19 hairy roots cultured for 21 days in MS liquid medium were harvested and dried in a circulating air oven. The dried material $(300 \mathrm{~g})$ was macerated in an ethanol:water (7:3) solution $(2 \mathrm{~L})$ for 7 days and then with methanol $(1 \mathrm{~L})$ for 7 days. The methanolic extract was evaporated to dryness and the dry residue $(60 \mathrm{~g})$ was solubilized in methanol:water (1:9), partitioned with hexane and then with ethyl acetate (thrice each). The aqueous fraction obtained from the ethyl acetate partition was further fractionated by multi-step solid phase extraction (SPE-C18) and semi-preparative HPLC. The protocol used in C-18 solid phase extraction SPE (Supelco; $1 \mathrm{~g}$ ) was as follows: the cartridge was conditioned with $6 \mathrm{~mL}$ of methanol and then with $6 \mathrm{~mL}$ of water. Then the crude extract ( $100 \mathrm{mg}$ dissolved in $6 \mathrm{~mL}$ of water) was loaded onto the cartridge. The cartridge was washed with $6 \mathrm{~mL}$ of water, $6 \mathrm{~mL}$ of 8:2 methanol-water and $6 \mathrm{~mL}$ of ethyl acetate (wash residues). The water fraction ( $40 \mathrm{mg}$ ) was then submitted to semi-preparative HPLC using the solvent system: 0-32' (10:66; A:B), 32-35' (66:10; A:B), $3 \mathrm{~mL} \cdot \mathrm{min}^{-1}$ flow rate, and detection at 330 and $350 \mathrm{~nm}$ during $40 \mathrm{~min}$ (A-water with $0,1 \%$ of acetic acid; $\mathrm{B}-\mathrm{MeOH}$ ); and an Agilent Zorbax Eclipse XDB-C18 column, $5 \mu$,
$250 \times 9.4 \mathrm{~mm}$, to yield 3,5-diCQA (10 mg). Purified 3,5diCQA was analyzed by one- and two-dimensional NMR in methanol-D4 using a Brüker® (Billerica, MA) BioSpin Avance $400 \mathrm{MHz}$ spectrometer. ESI-HR-MS was performed on a time-of-flight mass spectrometer (Jeol Accu TOF 4G, Tokyo, Japan).

\section{Results and discussion}

The E. prostrata (L.) L. hairy root $\mathrm{C} 19$ clone growth was evaluated for 21 days. In the first 3 days, the hairy roots were in the lag phase of growth, and the most intense cellular division occurred between the 6th and the 21st days of culture in which the fresh mass increased from $4.55 \mathrm{~g} / 100 \mathrm{~mL}$ on the 6th day up to $31.7 \mathrm{~g} / 100 \mathrm{~mL}$ on the $21 \mathrm{st}$ day, representing 1.3 fold increase at the beginning of the log phase and up to 14.9 fold increase at the end of the log phase (Supplementary data; Fig. S1). After 21 days, no mass increase was observed for the cultures indicating that the system reached the growth stationary phase and the death or decline phase was not observed in the course of experiments. The construction of growth curves allowed for the determination of the ideal time for addition of eliciting agents to cultures, which corresponds to the end of the logarithmic cell division phase. Obtained results indicated the 21 st day of culture growth as the most effective day for starting elicitation. The growth profile of E. prostrata (L.) L. hairy roots resemble Polygonum multiflorum hairy roots where it was found that the ideal time for the induction of anthraquinones was between the 18th and 21st days of elicitation (Huang et al. 2014). Similarly, studies have reported the 21 st day of elicitation as the end of the exponential growth phase of Artemisia annua hairy roots (Sivakumar et al. 2010). However, the $\log$ growth phase may vary depending on the plant species. Hairy roots of Rhaponticum carthamoides, also from the Asteraceae family, reported the period of 35 days for greatest mass production of fresh hairy roots (Skala et al. 2015).

Before elicitation and after 21 days of culture of the $E$. prostrata (L.) L. hairy root $\mathrm{C} 19$ clone, the ethanolic extracts from hairy root $\mathrm{C} 19$ clone was prepared and submitted to chromatographic procedures and semi-preparative HPLC. 3,5-diCQA was obtained as a white powder and characterized by MS and one- and two-dimensional NMR. NMR data showed three important signals from the aromatic ring at $\delta 7.05$ (s, H-2'/2'"), $\delta 6.79 ; 6.76(\mathrm{H}-5$ '/5' '), and $\delta 6.5$ (H-6'/6'), also the ${ }^{1} \mathrm{H}-\mathrm{NMR}$ spectrum showed two sets of double bonds $\mathrm{H}^{-}{ }^{\prime}$ ' and $\mathrm{H}-8$ ' at $\delta$ 7.61/7.54 and $\delta$ 6.33/ 6.21, respectively, related to caffeoyl moities. Signals of the quinic acid subunit were confirmed with the presence of methylene groups (C-2 and C-6) at $\delta 34.3$ and $\delta 36.2$ (Supplementary data; Table S1 and Fig. S2-S5). HRMS data confirm the proposed molecular formula (Supplementary data; Fig. 
<smiles>COc1cc(O)c2c(c1)oc(=O)c1c3cc(O)c(O)cc3oc21</smiles>

wedelolactone $(\mathrm{WL})$<smiles></smiles>

demethylwedelolactone (DWL)<smiles>O=C(/C=C/c1ccc(O)c(O)c1)O[C@H]1C[C@@](O)(C(=O)O)C[C@@H](OC(=O)/C=C/c2cccc(O)c2)[C@H]1O</smiles>

3,5-Di-O-caffeoylquinic acid (3,5-diCQA)

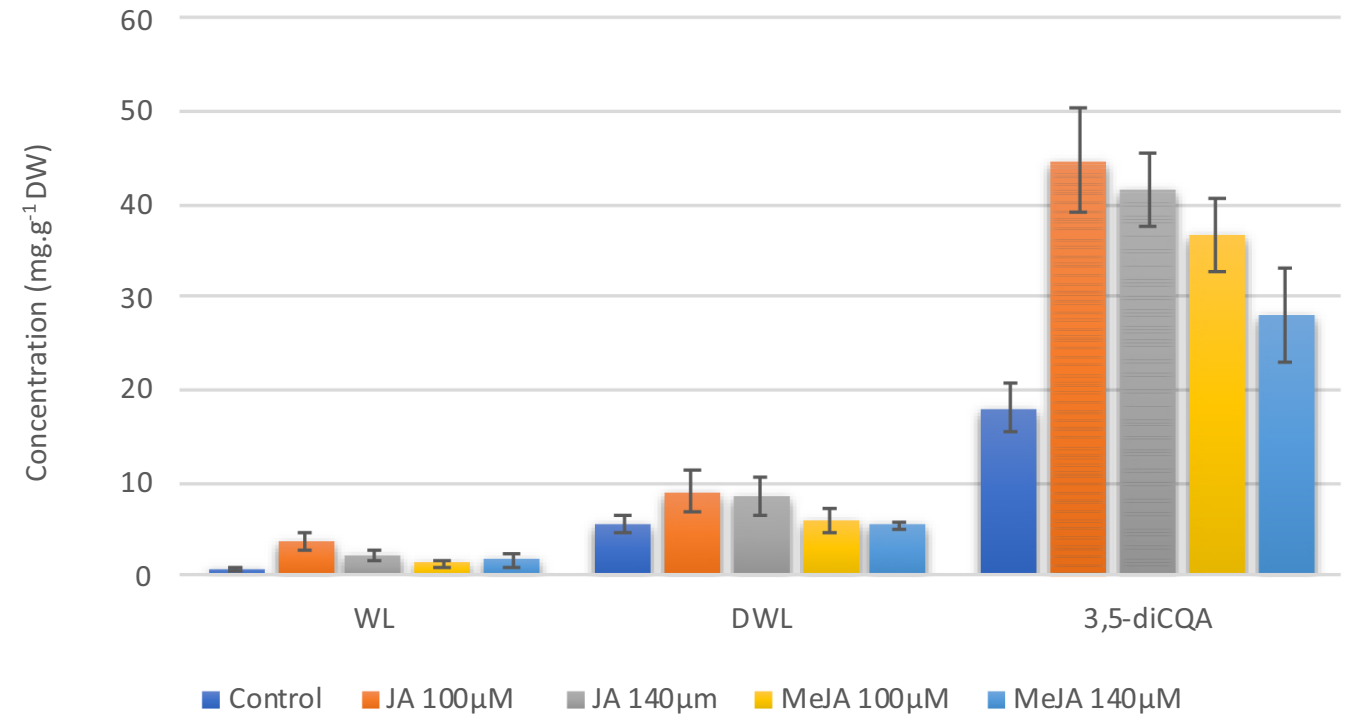

Fig. 1 Production of WL, DWL and 3,5-diCQA in E. prostrata (L.) L. hairy roots on 4th day of cultivation after elicitation with JA and MeJA

S6-S7). All NMR data allowed us to establish the structure of 3,5-diCQA in comparison with literature data (Wu et al. 2007; Wan et al. 2017).

Elicitation with JA and MeJA indicated that all variables analyzed (exposure period, type and concentration of the elicitor) affected the production of the target compounds WL, DWL and 3,5-diCQA, as shown in Fig. 1 (Supplementary data; Table S2). When examining WL production in hairy roots elicited with JA or MeJA, regarding exposure time, samples of all treatments collected 2 or 4 days after addition of elicitors showed an increased production of WL compared to control. Hairy roots elicited for 2 days presented an increase on WL production in the range of $1.30 \mathrm{mg} / \mathrm{g}$ d.w. and $1.20 \mathrm{mg} / \mathrm{g}$ d.w. for elicitation with $100 \mu \mathrm{M} \mathrm{JA}$ and $100 \mu \mathrm{M}$ MeJA and of $0.65 \mathrm{mg} / \mathrm{g}$ d.w. and $1.05 \mathrm{mg} / \mathrm{g}$ d.w. for $140 \mu \mathrm{M} \mathrm{JA}$ and $140 \mu \mathrm{M}$ MeJA, respectively, while the control produced $0.73 \mathrm{mg} / \mathrm{g}$ d.w. Moreover, hairy roots elicited for 4 days presented enhanced production of WL in all tested conditions, though it was observed that the best eliciting agent was JA in the concentration of $100 \mu \mathrm{M}$, which produced $3.72 \mathrm{mg} / \mathrm{g}$ d.w., thereby an increase of 5.2 fold in WL production if compared to the control which produced $0.72 \mathrm{mg} / \mathrm{g}$ d.w. Linear regression curves constructed for evaluating WL production after elicitation for 2 and 4 days showed that on the 2nd day there was no significant difference between elicitation with JA or MeJA agents; however, there was a correlation between dose and effect of elicitor once $100 \mu \mathrm{M}$ of either JA or MeJA induced higher stimulating effect than $140 \mu \mathrm{M}$. Regression analysis data showed that higher production of WL could be obtained in hairy roots elicited with $53 \mu \mathrm{M}$ of JA (Fig. 2A). Prolonged period of co-culture with JA resulted in more pronounced effect on the production of WL, $3.72 \mathrm{mg} / \mathrm{g}$ d.w., by roots exposed to $100 \mu \mathrm{M} \mathrm{JA}$, maximum yield at $78 \mu \mathrm{M}$ of JA, than those exposed to $140 \mu \mathrm{M} \mathrm{JA}$ (Fig. 2B).

In general, WL production in E. prostrata (L.) L. hairy roots was superior in cultures elicited by JA than in cultures elicited with MeJA. The best JA concentration on 2nd day should be $53 \mu \mathrm{M}$ whilst the best JA concentration on 4th day should be $78 \mu \mathrm{M}$, in follows that one could reduce elicitor dosage and save money. Hairy roots exposed to JA for 4 days showed enhanced DWL production compared to the control. Cultures elicited with $100 \mu \mathrm{M}$ JA produced $9.04 \mathrm{mg} / \mathrm{g}$ d.w. of DWL while those co-cultured with $140 \mu \mathrm{M}$ JA produced $8.63 \mathrm{mg} / \mathrm{g}$ d.w. of DWL. Obtained yields represent a 1.6 fold increase on DWL contents compared to the control.

Besides coumestans, E. prostrata (L.) L. hairy roots produced significant amounts of 3,5-diCQA, and the elicitation 

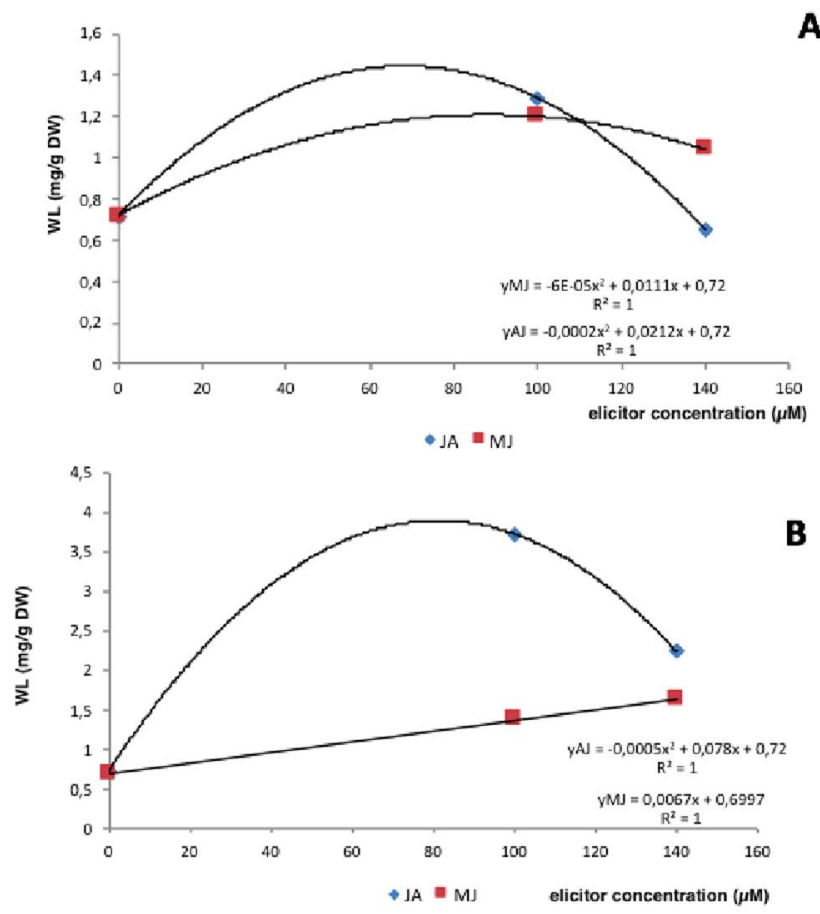

Fig. 2 Linear regression curves of WL and 3,5-diCQA produced by E. prostrata (L.) L. hairy roots as a function of period of elicitation and concentration of JA or MeJA elicitors. A WL after 2-day elicita-

using JA and MeJA improved the production in all treatments as compared to control (Fig. 1). Effects of a longer elicitation period were correlated with the elicitor concentration, and more enhanced production was observed in the roots harvested after a 4-day elicitation period. JA showed more effective results on the production of 3,5-diCQA producing $44.71 \mathrm{mg} / \mathrm{g}$ d.w. and $41.62 \mathrm{mg} / \mathrm{g}$ d.w. in cultures elicited for 4 days with $100 \mu \mathrm{M}$ and $140 \mu \mathrm{M} \mathrm{JA}$, respectively (the control produced $18.08 \mathrm{mg} / \mathrm{g}$ d.w.). Although a stimulating effect of MeJA was inferior when compared to JA, 3,5-diCQA yields ranged from $36.71 \mathrm{mg} / \mathrm{g}$ d.w. to $28.02 \mathrm{mg} / \mathrm{g}$ d.w. in hairy roots elicited with $100 \mu \mathrm{M}$ and $140 \mu \mathrm{M}$ MeJA, respectively (Fig. 1). When comparing 3,5diCQA production in the control culture it was possible to infer a production 2.5 and 2.3 fold superior in cultures elicited with $100 \mu \mathrm{M}$ and $140 \mu \mathrm{M} \mathrm{JA}$ and 2.0 and 1.5 fold in cultures elicited with $100 \mu \mathrm{M}$ and $140 \mu \mathrm{M}$ MeJA, respectively (Fig. 2). The best JA concentration on the 2nd day should be $112.16 \mu \mathrm{M}$ whilst the best JA concentration on the 4th day should be $102.34 \mu \mathrm{M}$. It is important to highlight that the JA concentration above $102.34 \mu \mathrm{M}$ reduced 3,5-diCQA production. Linear regression analysis (Fig. 2) indicated that secondary metabolite production in cultures elicited with JA was dependent on elicitor concentration, that is, the lower the elicitor concentration the superior the caffeoylquinic acid
A
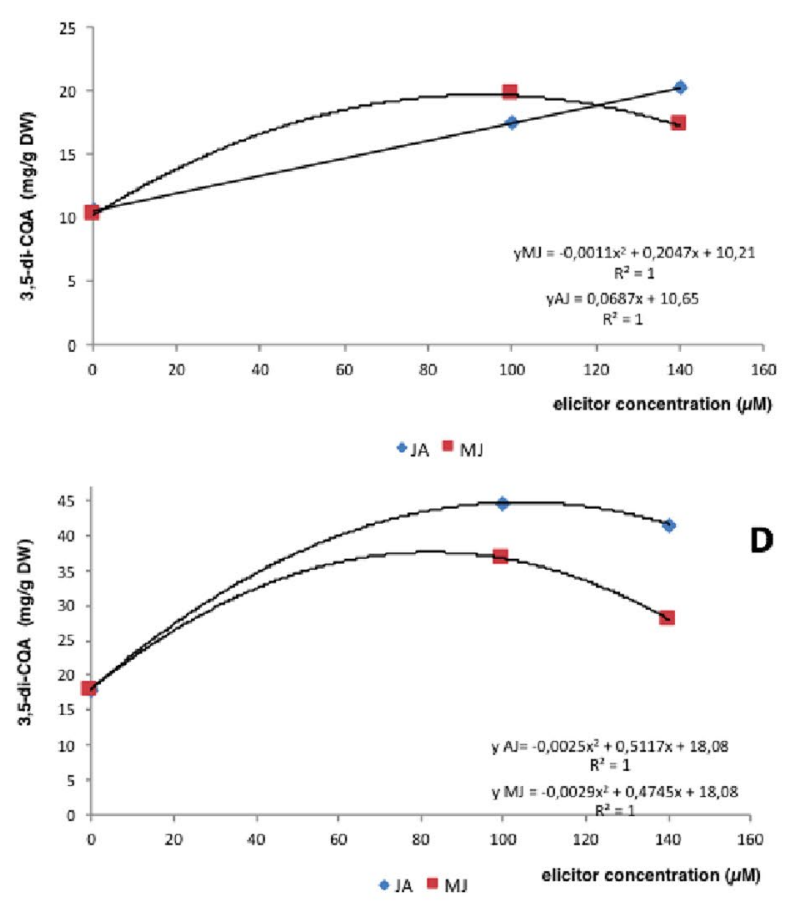

tion; B WL after 4-day elicitation; C 3,5-diCQA after 2-day elicitation; D 3,5-diCQA after 4-day elicitation

derivative production. Furthermore, cultures elicited with $140 \mu \mathrm{M}$ MeJA showed toxic effects and subsequent reduction in the production of target bioactives. Obtained results indicate that both elicitor agents added to E. prostrata (L.) L. hairy root cultures were able to improve production of the target compounds, but JA was more effective than MeJA.

The most elicited compound is the WL, followed by 3,5-diCQA and DWL respectively, suggesting that these chemical agents predominantly activate the enzymes of the phenylpropanoids via synthesis. WL achieved was 5.2 fold, while the yields of 3,5-diCQA and DWL were 2.5 and 1.6 fold higher, respectively (Fig. 3). WL is biosynthesized by shikimate and acetate pathways, has been a high commercial value, and considerable amounts were produced after elicitation experiments. The 3,5-diCQA is biosynthesized by the shikimate pathway and is generally involved in plant disease-resistance responses to biotic or abiotic stress (Wan et al. 2017). Recently, 3,5-diCQA has been shown as a high value biological compound because it displays in silico anti-covid-19 activity [30-31, 39-40] (Joshi et al. 2020; Shah et al. 2021; Sumon et al. 2021; Kadioglu et al. 2021) and E. prostrata (L.) L. hairy root cultures proved to be an exceptional biological source for high 3,5-diCQA biotechnological production. 
Fig. 3 Relative fold change of phenylpropanoids in E. prostrata (L.) L. hairy roots after elicitation with JA and MeJA on the 4th day

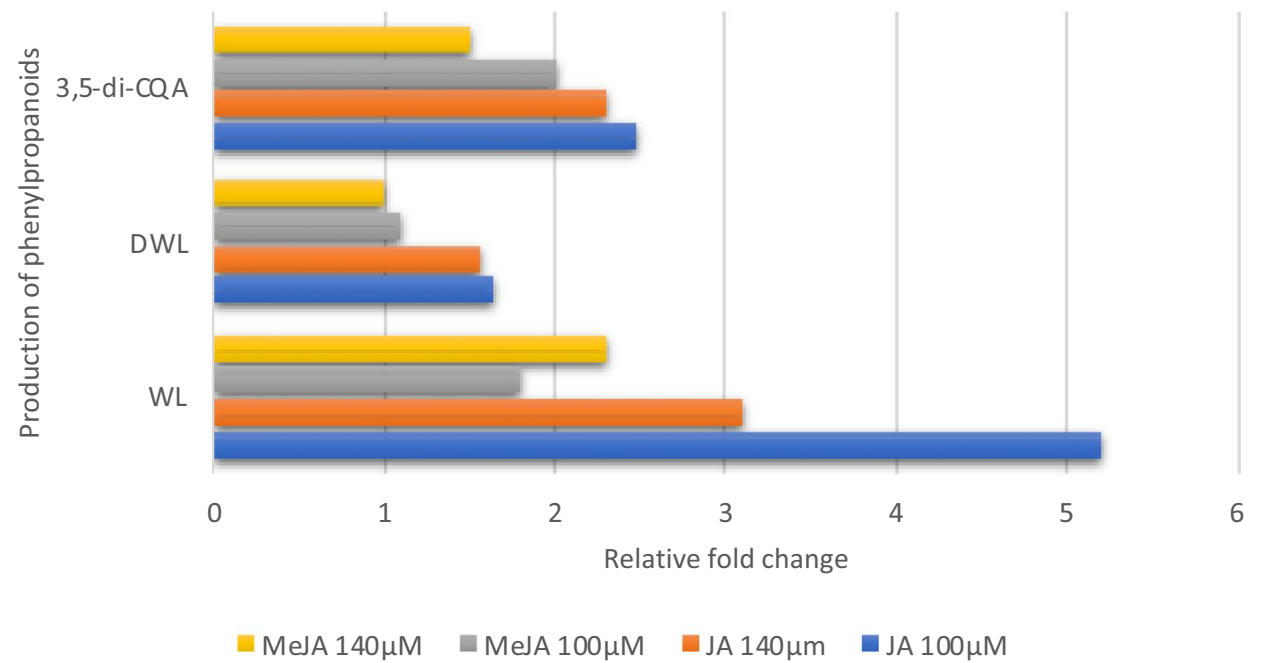

References

The biosynthesis of wedelolactone, demethylwedelolactone and 3,5-diCQA were positively influenced by elicitor concentration and elicitor exposure time of both chemical elicitors tested. The optimum period of co-cultivation with each elicitor was 4 days. Compared to controls, the highest yield of WL achieved was a 5.2 fold increase, while the yields of 3,5-diCQA and DWL were 2.5 and 1.6 fold higher, respectively. Under these conditions, $E$. prostrata (L.) L. hairy roots cultures showed productivity of $0.15 \mathrm{mg} / \mathrm{g} /$ day of WL, $0.36 \mathrm{mg} / \mathrm{g} /$ day of DWL and $1.19 \mathrm{mg} / \mathrm{g} / \mathrm{day}$ of 3,5-diCQA. Obtained data validate the potential of E. prostrata (L.) L. elicited hairy root cultures as an efficient system for the production of bioactive phenylpropanoids, specially the 3,5-diCQA, a potential anti-Covid-19 therapeutic agent as determined by computational evidence.

Supplementary Information The online version contains supplementary material available at https://doi.org/10.1007/s11240-021-02201-4.

Acknowledgements The authors are grateful to the Biotechnology Unit (UNAERP).

Author contributions MVL and AAL conceived the study design; GM carried out the experiments; SCF, MVL, AAL and BWB analyzed and interpreted data; CLC carried out the identification of the compounds, MVL prepared the draft manuscript; SCF, AAL made a critical revision of the manuscript; and all authors approved the manuscript.

\section{Declarations}

Conflict of interest The authors declare that they have no conflict of interest.
Ali F, Khan BA, Sultana S (2016) Wedelolactone mitigates UVB induced oxidative stress, inflammation and early tumor promotion events in murine skin: plausible role of NFkB pathway. Eur J Pharmacol 786:253-264

Ali N, Rashid S, Nafees S, Hasan SK, Shahid A, Majed F, Sultana S (2017) Protective effect of chlorogenic acid against methotrexate induced oxidative stress, inflammation and apoptosis in rat liver: an experimental approach. Chem Biol Interact 272:80-91

Cardarelli M, Mariotti D, Pomponi M, Spano L, Carone I, Costantino P (1987) Agrobacterium rhizogenes T-DNA genes capable of inducing hairy root phenotype. Mol Gen Genet 209:475-480

Chaudhary H, Dhuna V, Singh J, Kamboj SS, Sriram S (2011) Evaluation of hydro-alcoholic extract of Eclipta alba for its anticancer potential: an in vitro study. J Ethnopharmacol 136:363-367

Cheng M, Hu ZH (2010) Advances in studies on biology and chemical constituents in dried aerial part of Eclipta prostrata. Chin Tradit Herb Drugs 41:2116-2118

Devrnja N, Krstić-Milošević D, Janošević D, Tešević V, Vinterhalter B, Savić J, Ćalić D (2020) In vitro cultivation of tansy (Tanacetum vulgare L.): a tool for the production of potent pharmaceutical agents. Protoplasma 258:587-599

Diogo LC, Fernandes RS, Marcussi S, Menaldo DLG, Roberto PG, Matrangulo PVF, Pereira PS, França SC, Giuliatti S, Soares AM, Lourenço MV (2009) Inhibition of snake venoms and phospholipases A2 by extracts from native and genetically modified Eclipta alba: isolation of active coumestans. Basic Clin Pharmacol Toxicol 104:293-299

Espinosa-Leal CA, Puente-Garza CA, García-Lara S (2018) In vitro plant tissue culture: means for production of biological active compounds. Planta 248:1-18

Ferreira DF (2011) Sisvar: a computer statistical analysis system. Cienc Agrotec 35:1039-1042

Han L, Zhao J, Zhang Y, Kojo A, Liu E, Wang T (2013) Chemical constituents from dried aerial parts of Eclipta prostrata. Chin Herb Med 5:313-316

Huang B, Lin H, Yan C, Qiu H, Qiu L, Yu R (2014) Optimal inductive and cultural conditions of Polygonum multiflorum transgenic hairy roots mediated with Agrobacterium rhizogenes $\mathrm{R} 1601$ and 
an analysis of their anthraquinone constituents. Pharmacogn Mag 10:77-82

Joshi T, Joshi T, Sharma P, Mathpal S, Pundir H, Bhatt V, Chandra S (2020) In silico screening of natural compounds against COVID19 by targeting Mpro and ACE2 using molecular docking. Eur Rev Med Pharmacol Sci 24:4529-4536

Kadioglu O, Saeed M, Greten HJ, Efferth T (2021) Identification of novel compounds against three targets of SARS CoV-2 coronavirus by combined virtual screening and supervised machine learning. Comput Biol Med 133:104359

Lee KY, Ha NR, Kim TB, Kim YC, Sung SH (2010) Characterization of triterpenoids, flavonoids and phenolic acids in Eclipta prostrata by high-performance liquid chromatography/diode-array detector/ electrospray ionization with multi-stage tandem mass spectroscopy. Nat Prod Sci 16:164-168

Lee YJ, Lin WL, Chen NF, Chuang SK, Tseng TH (2012) Demethylwedelolactone derivatives inhibit invasive growth in vitro and lung metastasis of MDA-MB-231 breast cancer cells in nude mice. Eur J Med Chem 56:361-367

Lin FM, Chen LR, Lin EH, Ke FC, Chen HY, Tsai MJ, Hsiao PW (2007) Compounds from Wedelia chinensis synergistically suppress androgen activity and growth in prostate cancer cells. Carcinogenesis 28:2521-2529

Liu Z-B, Chen J-G, Yin Z-P, Shangguan X-C, Peng D-Y, Lu T, Lin P (2018) Methyl jasmonate and salicylic acid elicitation increase content and yield of chlorogenic acid and its derivatives in Gardenia jasminoides cell suspension cultures. Plant Cell Tiss Organ Cult 134:79-93

Lourenço MV, Soares W, Bertoni BW, Oliveira AP, Pereira SIC, Pereira AMS, Franca SC (2016) Eliciting effect of jasmonates from Botryosphaeria rhodina enhances coumarin production in Mikania laevigata plants. Plant Cell Tiss Org Cult 125:595-598

Lu Y, Hu D, Ma S, Zhao X, Wang S, Wei G, Wang X, Wen A, Wang J (2016) Protective effect of wedelolactone against CCl4-induced acute liver injury in mice. Int Immunopharmacol 34:44-52

Malla MY, Sharma M, Saxena RC, Mir MI, Mir AH, Hussain A, Bhat SH (2013) Phytochemical screening and spectroscopic determination of total phenolic and flavonoid contents of Eclipta alba Linn. J Nat Prod Plant Resour 3:86-91

Manvar D, Mishra M, Kumar S, Pandey VN (2012) Identification and evaluation of anti hepatitis $\mathrm{C}$ virus phytochemicals from Eclipta alba. J Ethnopharmacol 144:545-554

Murashige T, Skoog F (1962) A revised medium for rapid growth and bio-assays with tobacco tissue cultures. Physiol Plant 15:473-497

Sák M, Dokupilová I, Kaňuková Š, Mrkvová M, Mihálik D, Hauptvogel P, Kraic J (2021) Biotic and abiotic elicitors of stilbenes production in Vitis vinifera L. cell culture. Plants (basel) 10:490

Schmülling T, Shell J, Spena A (1988) Single genes from Agrobacterium rhizogenes influence plant development. EMBO J 7:2621-2629

Scott AJ, Knott MA (1974) A cluster analyses method for grouping means in the analyses of variance. Biometics 30:507-512

Shah S, Chaple D, Arora S, Yende S, Mehta C, Nayak U (2021) Prospecting for cressa cretica to treat COVID-19 via in silico molecular docking models of the SARS-CoV-2. J Biomol Struct Dyn $15: 1-10$
Sivakumar G, Liu C, Weathers JP (2010) Biomass production of hairy roots of Artemisia annua and Arachis hypogaea in a scaled-up mist bioreactor. Biotechnol Bioeng 107:802-813

Skala E, Kicel A, Olszewska MA, Kiss AK, Wysokinska H (2015) Establishment of hairy root cultures of Rhaponticum carthamoides (Willd) Iljin for the production of biomass and caffeic acid derivatives. Biomed Res Int 2015:181098

Souza LSA, Silva JF, Souza MDB (2003) Composição florística de plantas daninhas em agrossistemas de cupuaçuzeiro (Theobroma grandiflorum) e pupunheira (Bactris gasipaes). Planta Daninha 21:249-255

Spena A, Schmülling T, Koncz C, Schell JS (1987) Independent and synergistic activity of rol A B and C loci in stimulating abnormal growth in plants. EMBO J 6:3891-3899

Sumon TA, Hussain MA, Hasan MT, Hasan M, Jang WJ, Bhuiya EH, Chowdhury AAM, Sharifuzzaman SM, Brown CL, Kwon HJ, Lee EW (2021) A revisit to the research updates of drugs, caccines, and bioinformatics approaches in combating COVID-19 pandemic. Front Mol Biosci 25:585899

Syed SD, Deepak M, Yogisha S, Chandrashekar AP, Muddarachappa KA, D'Souza P, Agarwal A, Venkataraman BV (2003) Trypsin inhibitory effect of wedelolactone and demethylwedelolactone. Phytother Res 17:420-421

Tsai CH, Lin FM, Yang YC, Lee MT, Cha TL, Wu GJ, Hsieh SC, Hsiao PW (2009) Herbal extract of Wedelia chinensis attenuates androgen receptor activity and orthotopic growth of prostate cancer in nude mice. Clin Cancer Res 15:5435-5444

Wagner H, Fessler B (1986) In vitro 5-lipoxygenase inhibition by Elipta alba extracts and the Coumestans derivative wedelolactone. Planta Med 5:374-377

Wan C, Li S, Liu L, Chen C, Fan S (2017) Caffeoylquinic acids from the aerial parts of Chrysanthemum coronarium L. Plants (basel) $17: 10$

Wiktorowska E, Długosz M, Janiszowska W (2010) Significant enhancement of oleanolic acid accumulation by biotic elicitors in cell suspension cultures of Callendula officinalis L. Enzyme Microb Technol 46:14-20

Wu C, Chen F, Wang X, Wu Y, Dong M, He G, Galyean RD, He L, Huang G (2007) Identification of antioxidant phenolic compounds in feverfew (Tanacetum parthenium) by HPLC-ESI-MS/MS and NMR. Phytochem Anal 18:401

Wu T, Abdulla R, Yang Y, Aisa HA (2008) Flavonoids from Gossypium hirsutum flowers. Chem Nat Compd 44:370-371

Yahara S, Ding N, Nohara T (1994) Oleanane glycosides from Eclipta alba. Chem Pharm Bull 42:1336-1338

Yuan F, Chen J, Sun PP, Guan S, Xu J (2013) Wedelolactone inhibits LPS-induced pro-inflammation via NF-kappaB pathway in RAW 264.7 cells. J Biomed Sci 20:84

Zhang JS, Guo QM (2001) Studies on the chemical constituents of Eclipta prostrata. Acta Pharm Sin 36:34-37

Publisher's Note Springer Nature remains neutral with regard to jurisdictional claims in published maps and institutional affiliations. 